\section{Climate justice more vital than democracy}

Decision-making based on social-justice principles could be more effective than democratic efforts against climate change (see N. Stehr Nature 525, 449-450;2015).

Democratic decision-making involves multiple stakeholders, and democracy emphasizes the mutual roles of actors: all preferences are treated as equal. In many regions of the world, however, the results of democratic choices can be strongly influenced by power relations and inequitable social arrangements, owing to differences in economic development, access to technology and knowledge.

Elites may use democratic processes to entrench their status or encroach on other social goals (B. Sovacool et al. Nature Clim. Change 5, 616-618; 2015). This can lead to incremental or undesirable results, which might explain why large democratic nations such as the United States continue to oppose progressive climate legislation.

In our view, sound climate and energy planning should not treat all stakeholders in the same way. Instead, preferences and roles should be weighted to consider criteria related to equity, due process, ethics and other justice principles. This would ensure that stakeholder discussions and resulting policies serve to eradicate, rather than exacerbate, socio-economic vulnerability to a changing climate.

Jingzheng Ren, Michael Evan Goodsite University of Southern Denmark, Odense, Denmark. Benjamin K. Sovacool Aarhus University, Herning, Denmark. benjaminso@auhe.au.dk

\section{Interdisciplinarity: two more principles}

As scientists in a sustainabledevelopment research institute, our experience has demonstrated two further principles that are crucial for successful interdisciplinary research

(see R. R. Brown et al. Nature 525,

315-317; 2015).

First, solving real-world problems requires integration of the social and biophysical realms. Key to this is the explicit consideration of differences in scale. For example, water governance has a typical time horizon of years, yet hydrological processes operate on timescales from seconds to millennia.

Second, a critical mass of interdisciplinary scholars is necessary to become a credible counterpart for disciplinary researchers and to catalyse progress. Our institute employs 150 interdisciplinary researchers, who engage much greater numbers of single-discipline researchers in interdisciplinary projects.

Martin J. Wassen, Marko P.

Hekkert Utrecht University, the Netherlands.

m.j.wassen@uu.nl

\section{Interdisciplinarity: topping the charts}

We offer ideas on why India ranks highest and Brazil fifth - above the United States and Europe - in terms of the numbers of interdisciplinary research papers that they publish in Elsevier journals (see Nature 525, 306-307; 2015).

India's researchers are surrounded by dynamic ecological, social and economic problems. They therefore naturally turn to solutionoriented research that is informed by the complexity of their environment. Although interdisciplinary researchers still struggle for acceptance in India's traditional, rigidly structured university departments, new universities with centralized programmes are offering fresh and tempting perspectives.

In Brazil, the number of interdisciplinary graduate programmes is growing twice as fast as the number of disciplinary courses. The country's national accreditation system changed
15 years ago, when many of its master's and $\mathrm{PhD}$ programmes failed to fit any of their set 46 disciplinary slots.

Marcel Bursztyn University of Brasília, Brazil.

Seema Purushothaman Azim

Premji University, Bangalore, India. marcel@unb.br

\section{Restore vaccine trust in Japan}

Vaccination coverage for human papilloma virus (HPV) in Japan has plummeted following unconfirmed media reports of severe adverse reactions such as chronic pain and cognitive decline (see S. J. B. Hanley et al. Lancet 385, 2571; 2015). In response, and presumably to avoid lawsuits, the government has suspended its proactive vaccination recommendation.

Several scandals in the past few decades have fuelled the Japanese public's scepticism. These include health hazards associated with some drugs and vaccines, widely publicized cases of misconduct among researchers, and questionable connections between medical professionals and pharmaceutical companies (see T. Tanimoto et al. Nature 512, 371; 2014).

At the heart of the debate is Japan's compensation scheme for vaccine injury, which depends on a causal relationship being confirmed by the government. Claimants may also seek further compensation through private litigation against the government. In most countries, claimants must pursue one scheme or the other, not both.

In our view, the government should introduce a no-fault compensation system, following the lead of other countries, including the United States and Scandinavian nations (see C. Looker and H. Kelly Bull. World Health Organ. 89, 371-378; 2011). Exemption from liability would make for a fairer and more transparent judgement in policymaking and pave the way for a new Japanese vaccination programme in which public trust is restored.

Tetsuya Tanimoto, Eiji Kusumi Navitas Clinic, Tokyo, Japan. Claire Leppold University of Edinburgh, UK. tetanimot@yahoo.co.jp

\section{Some rules for behavioural science}

US President Barack Obama's executive order of 15 September, 'Using behavioral science insights to better serve the American people', is intended to strengthen the policymaking process. To prevent the Obama administration from falling victim to agendas backed by pseudoscience, I suggest that it should consider only studies that abide by certain established rules.

The rules were instituted in behavioural and experimental economics research in universities, largely in response to scientific misconduct by governments and academics. They stipulate that an independent ethics committee must review research involving human subjects before the start of any experiment; that participants should first give their informed consent; and that they should receive appropriate remuneration to ensure that their decisions reflect genuine preferences. Moreover, deception should never be used in experimental design or in the process of scientific enquiry.

In the interests of scientific transparency, studies that lead to policy change should be peer reviewed and experimental design details and data made publicly available.

Such guidelines would help to ensure that studies are relevant, rigorous, ethical and legal. They would also provide a means to replicate and test studies for bias, efficacy and accuracy.

Jason A. Aimone Baylor University, Waco, Texas, USA. jason_aimone@baylor.edu 